\title{
COMPARATIVE SURFACE DAMAGE DETERMINATION AT A JEWISH GRAVE USING TWO DIFFERENT MOBILE ULTRASONIC VELOCITY DEVICES
}

\author{
Christaras B. ${ }^{1}$, Moropoulou An. ${ }^{2}$, Chatziangelou M. ${ }^{1}$, Dimitraki L. ${ }^{1}$ and \\ Devlioti K. ${ }^{1}$ \\ ${ }^{\text {IS }}$ chool of Geology, Aristotle University of Thessaloniki, christar@geo.auth.gr, \\ mcha@geo.auth.gr,lambrinidil@yahoo.gr,kdevlioti@yahoo.gr \\ ${ }^{2}$ School of Chemical Engineering, National Technical University of Athens, \\ amoropul@central.ntua.gr
}

\begin{abstract}
The non-destructive methods are necessary in the investigation of the physical and mechanical properties of the materials in monuments. In this framework the ultrasonic velocities were used in situ for the elaboration and evaluation of the weathering on the surfaces of monuments. Additionally, the P-wave velocities were used for the estimation of the depth of weathered zone, as well as the depth of cracks at the surface of the monument. This estimation was performed on a Jewish tomb placed in the AUTH university campus between the building of Law and Economic Sciences and the Administration building, of the Aristotle University of Thessaloniki. Keywords: non-destructive methods; ultrasonic velocities; historical monument; surface weathering degree; depth of cracks.
\end{abstract}

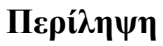

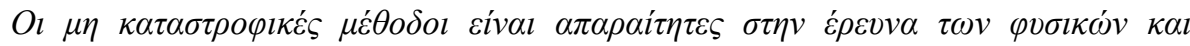

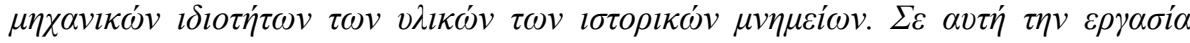

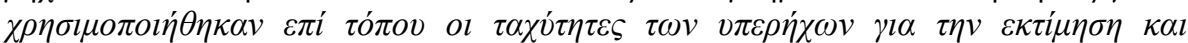

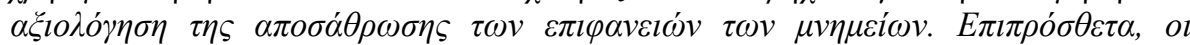

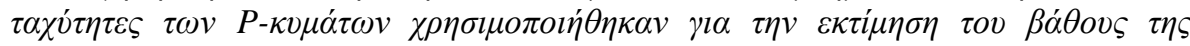

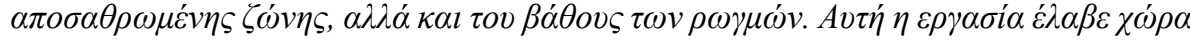

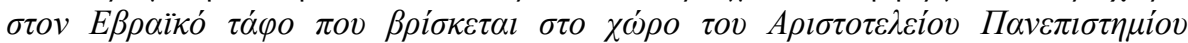

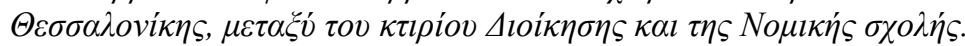

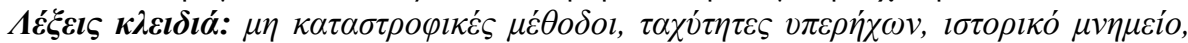

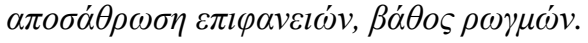

\section{Introduction}

The ultrasonic velocity method is an in situ, Non-Destructive technique which is used for the evaluation of surface conditions on historical monuments, without receiving testing materials. The results give the opportunity of recording and evaluating data, consisting major factors of quality and weathering of the surfaces. The implementation of this method took place in one of the most 
impressive monuments in the Aristotle University of Thessaloniki (Christaras, 2009), (Figure 1, Figure 2).

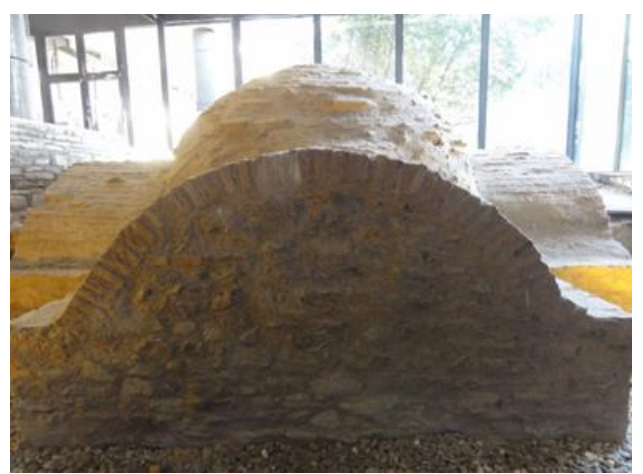

Figure 1 - A general option of the monument.

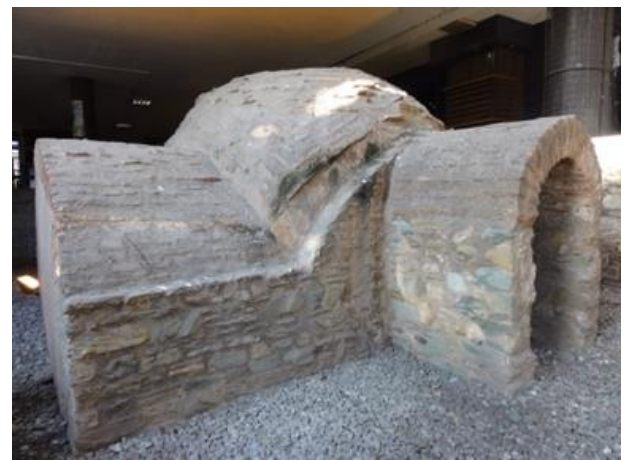

Figure 2 - The entrance of the monument.

This tomb dates in the first quarter of $4^{\text {th }}$ century and belongs to a member of Israelite community in Thessaloniki and was founded in university campus between the central administration building and the building of Law and Economic Sciences. It is about a well-preserved historical monument with favorable position for taking the ultrasonic measurements (Marki, 2001).

\section{Methodology}

For evaluating the weathering degree of the monument surfaces were used two ultrasonic devices, the SURFER ultrasonic detector (Figure 3) and the PUNDIT ultrasonic non-destructive digital tester (Figure 4), (Bruneau et al., 1995). The SURFER detector is applicable for measurement of ultrasound velocity and time of longitudinal ultrasound waves propagation in solid materials at surface sounding testing method for estimating the quality of the materials. This estimation is based on the correlation of ultrasound waves velocity in material to its physic and mechanical characteristics and physical statement. The SURFER gives the chance of estimating the depth of the crack $(\mathrm{mm})$ on the surface by calculating the time of ultrasonic waves propagation. This device maintains a stable distance between the two ultrasonic probes $(15 \mathrm{~cm})$ which gives the ability of mapping and allocating the weathering of specific surfaces.

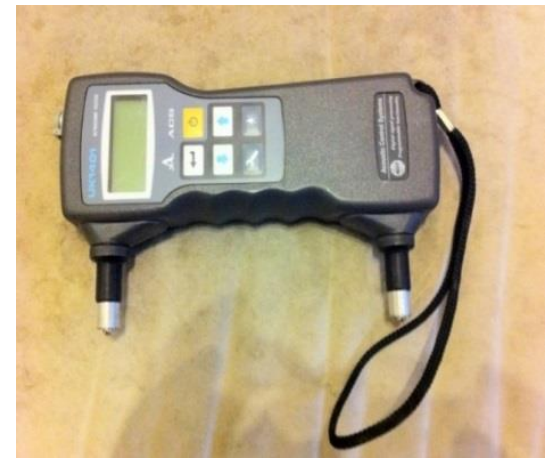

Figure 3 - The SURFER ultrasonic detector.

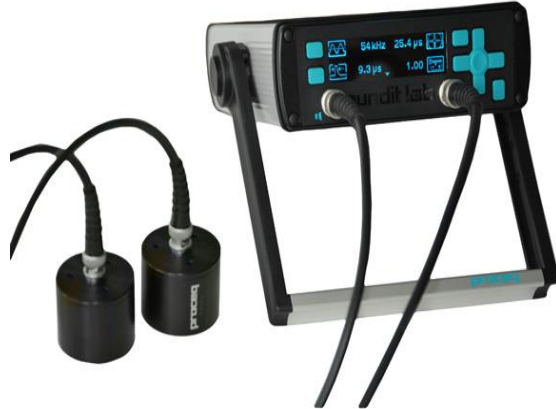

Figure 4 - The PUNDIT ultrasonic device.

On the other hand, the PUNDIT ultrasonic non-destructive digital tester is a good index characteristic for determining the physic-mechanical behavior and evaluating the weathering degree 
of the rocks. For the measurements a pair of small edge transducers was used for estimating the Pwave velocity for the determination of the depth. The tests held out by using the indirect method referring to arrangement of the transducers (transmitter and receiver) on the same surface of the stone. The transmitter was stable along a calibrated line and the receiver was reinstalling at every $5 \mathrm{~cm}$. The final result was the travel time in correlation with the distance in each place. Each pair (travel time-distance) is displayed on a diagram. Given the fact, that the most weathered surface demands longer travel time propagation, the change of slope in the plot indicates the quality of the material.

The lower velocity in the surface zone is the result of the stone surface weathering. According to this plot, the thickness of the weathered surface layer is estimated as follows: [Vs: pulse velocity in the sound rock $(\mathrm{Km} / \mathrm{s})$, Vd: velocity in the damaged rock $(\mathrm{Km} / \mathrm{s})$, Xo: horizontal distance at which the change of slope occurs (mm), D: depth of weathering (mm)] (Bruneau et al., 1995):

\section{Equation 1 - Formula for estimating the thickness of the weathered surface.}

$$
D=\frac{X o}{2} \sqrt{(V s-V d) /(V s+V d)}
$$

\section{Application of the method}

First of all, the SURFER device was used for mapping 4 specific surfaces of the monument (the back surface, the convex one upon the back surface, the dome and the entrance of the tomb), by taking a big amount of measurements, approximately 459, (Figure 5).

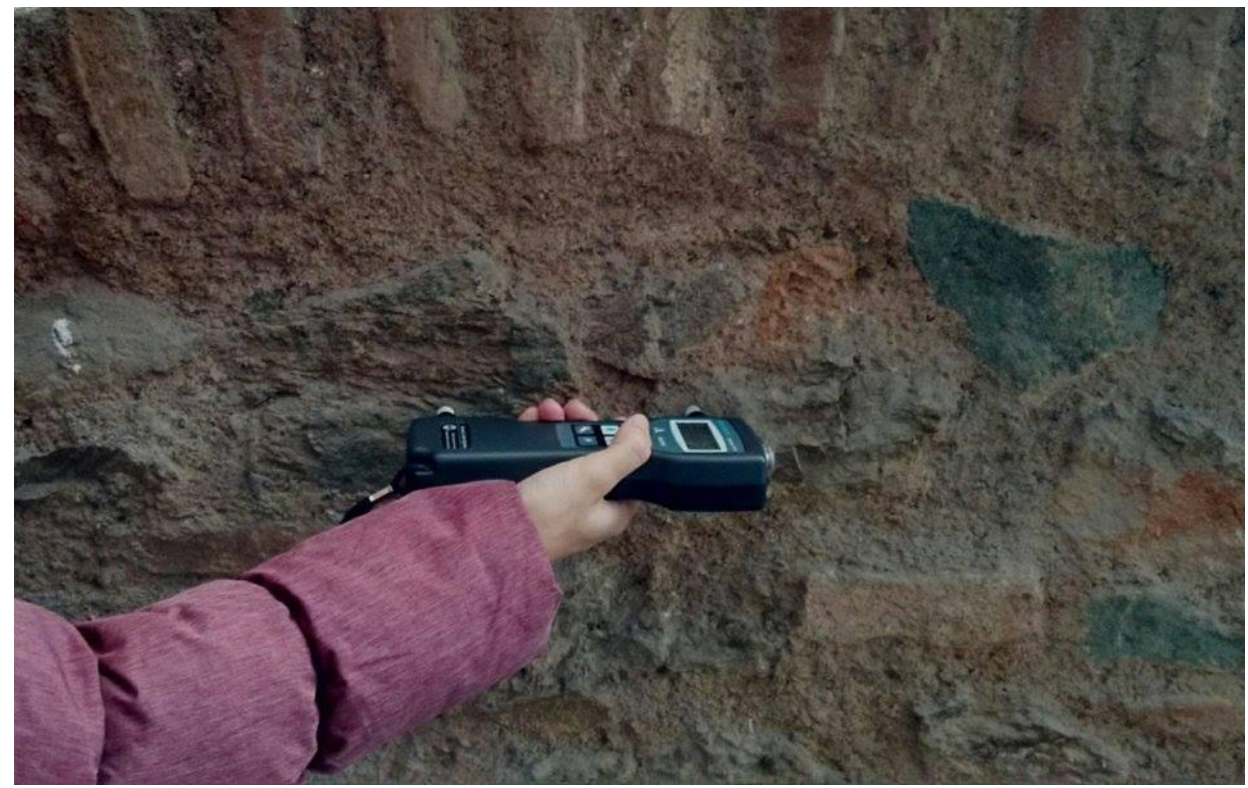

Figure 5 - The use of SURFER device on the monument.

The application of this method was implemented for the allocation of the weathering along these surfaces, by the construction of 4 maps. Each map depicts the ultrasonic velocities $\mathrm{Vp}(\mathrm{m} / \mathrm{sec})$ and the way they are distributed depending on the weathering conditions of each surface. The most weathered parts take lower values (longer travel time propagation), so in Figure 6 (back surface), it is obvious that the biggest part (in the right part and left half part of the tomb) is displayed with the lightest colors, assigning the most weathered areas, with $\mathrm{Vp}=1200-2000 \mathrm{~m} / \mathrm{sec}$ in the first most weathered part and $\mathrm{Vp}=800-2000 \mathrm{~m} / \mathrm{sec}$ in the second most weathered part of the back surface. 


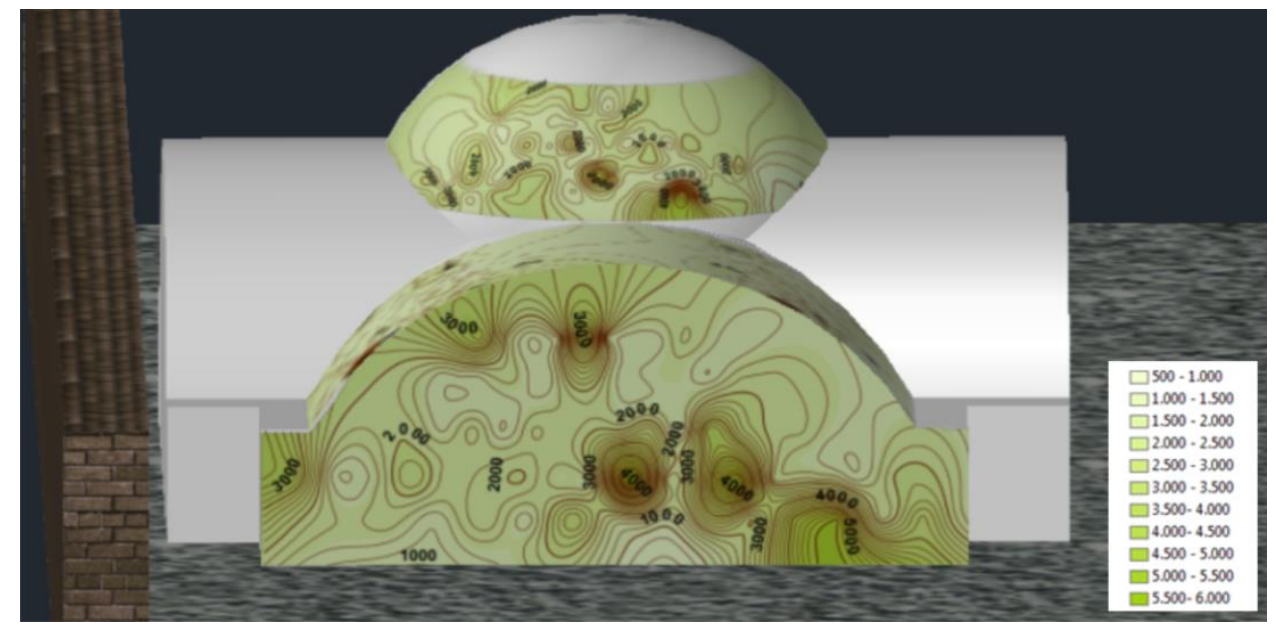

Figure 6 - The back surface of the monument (the maps were made with ARC GIS 2010, on the model by the use of the AutoCAD 2012. The legend shows the ultrasound velocities Vp (m/sec).

At the same way, along the convex part, upon the back surface appears clearly the weathered part, the values of which range in lower levels than those in the back surface, with $\mathrm{Vp}=500-2000 \mathrm{~m} / \mathrm{sec}$ (Figure 7).

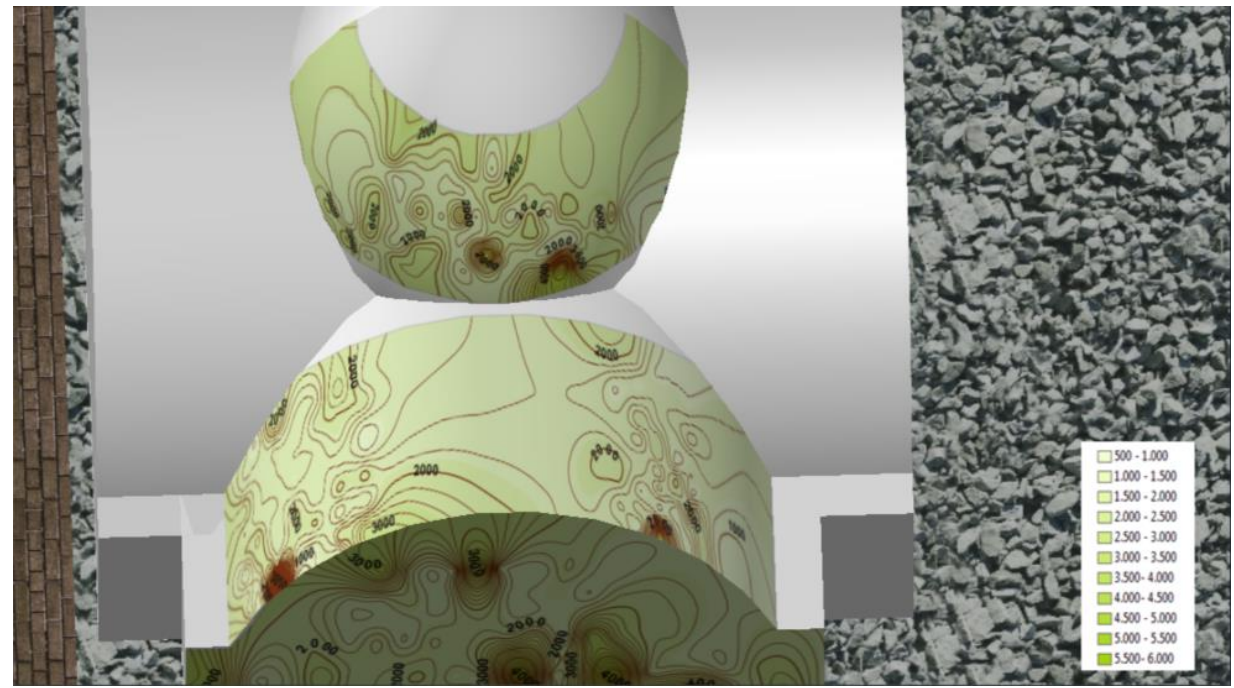

Figure 7 - The convex part upon the back surface, (the maps were made with ARC GIS 2010 on the model, by the use of the AutoCAD 2012). The legend shows the ultrasound velocities $\mathrm{Vp}(\mathrm{m} / \mathrm{sec})$.

In Figure 8, the dome of the monument appears to have a wide weathered area which ranges between 1000- $2000 \mathrm{~m} / \mathrm{sec}$.

Finally, at the entrance of the tomb, there are distinguished 2 weathered areas that appear to have the same values both in the right and in the left semicircular part. The values of the velocity range at a width of 1800-2000 m/sec, (Figure 9 and 10). 


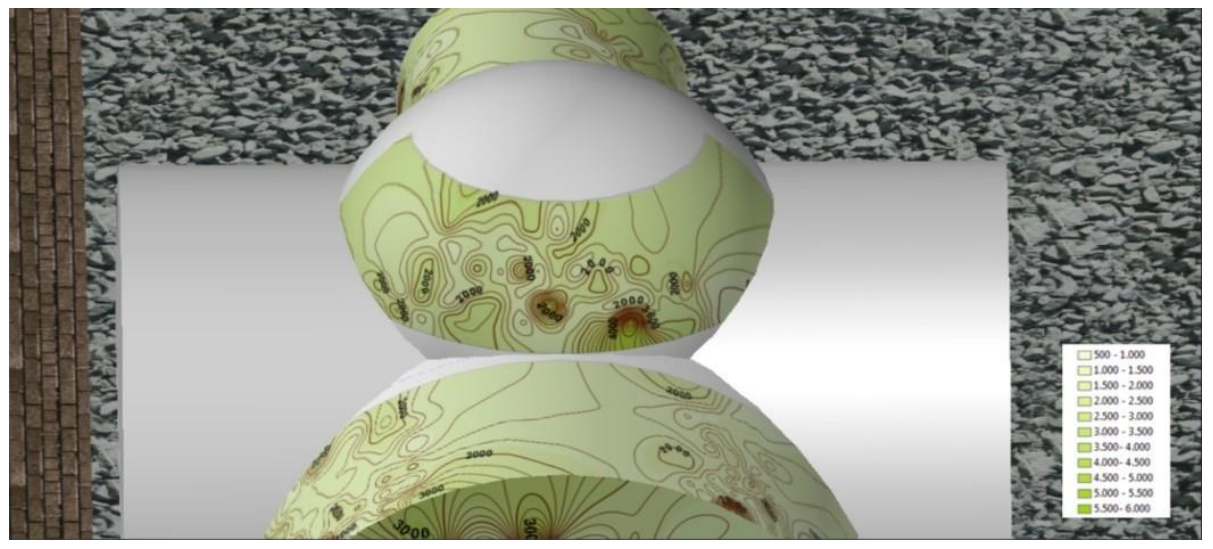

Figure 8 - The dome of the monument, (the maps were made with ARC GIS 2010 on the model, by the use of the AutoCAD 2012). The legend shows the ultrasound velocities $\mathrm{Vp}(\mathrm{m} / \mathrm{sec})$.

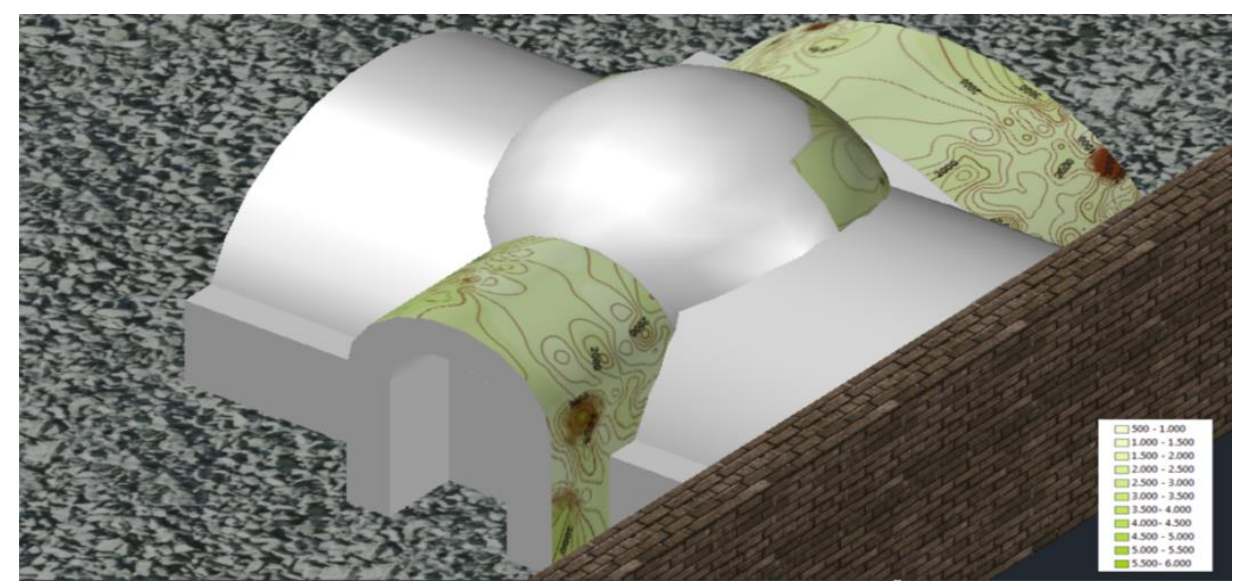

Figure 9 - The right part of the entrance, (the maps were made with ARC GIS 2010 on the model, by the use of the AutoCAD 2012). The legend shows the ultrasound velocities $\mathrm{Vp}(\mathrm{m} / \mathrm{sec})$.

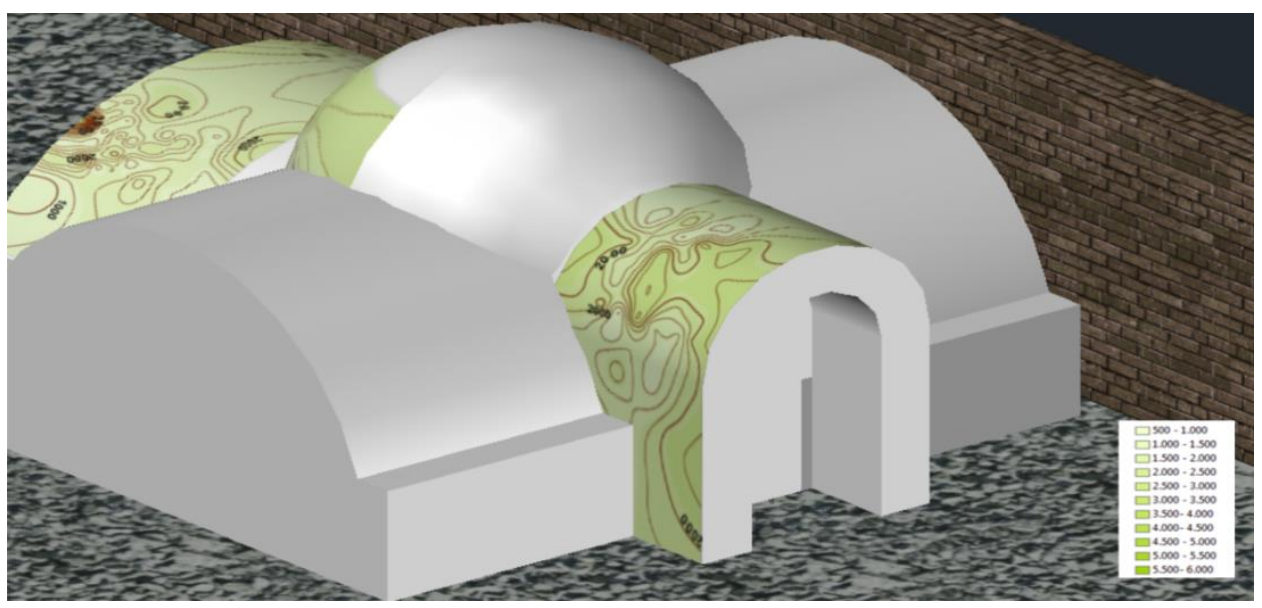

Figure 10- The left part of the entrance, (the maps were made with ARC GIS 2010 on the model, by the use of the AutoCAD 2012). The legend shows the ultrasound velocities $\mathrm{Vp}(\mathrm{m} / \mathrm{sec})$. 
Except for the SURFER device, PUNDIT Ultrasonic non-destructive digital tester also was used for determining the physic and mechanical characteristics and evaluating the weathering depth. For the purposes of the measurements, the indirect method was used. The final result was the travel time in correlation with the distance in each place. As it is known in Figure 11, the most weathered surface needs longer travel time propagation, so the change of slope in the plot indicates the quality of the material.

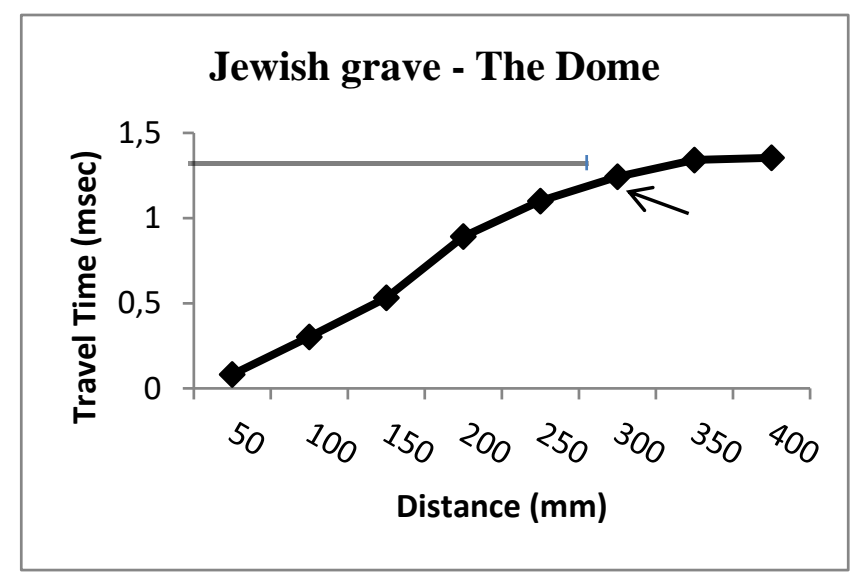

Figure 11 - Estimation of the weathering depth on the surface of the dome in the Jewish grave.

According to the Equation 1 was estimated the depth of each weathered zone of the surfaces of the monument. In detail, the back surface was devised in two areas: in the first area the depth was calculated in $\mathrm{D}=66 \mathrm{~mm}$, while in the second one was $\mathrm{D}=92.4 \mathrm{~mm}$. At the same way, the depth of the weathering at the convex part upon the back surface is about $\mathrm{D}=83 \mathrm{~mm}$ and the dome as it is shown in the following plot Figure 11, the travel time of P-waves is constant in depth higher than $\mathrm{D}=35 \mathrm{~mm}$. Furthermore, the entrance of the tomb consists of the right side with weathering depth $\mathrm{D}=79 \mathrm{~mm}$ and the left one with the same weathering depth.

As it was mentioned before, the SURFER device gives the opportunity of determining the depth of the cracks of the surfaces. On the back surface of the monument are distinguished two cracks Figure 12 , the depths of which were measured as follows: for the first crack the depth is $D=88 \mathrm{~mm}$, while for the second one is $\mathrm{D}=45 \mathrm{~mm}$.

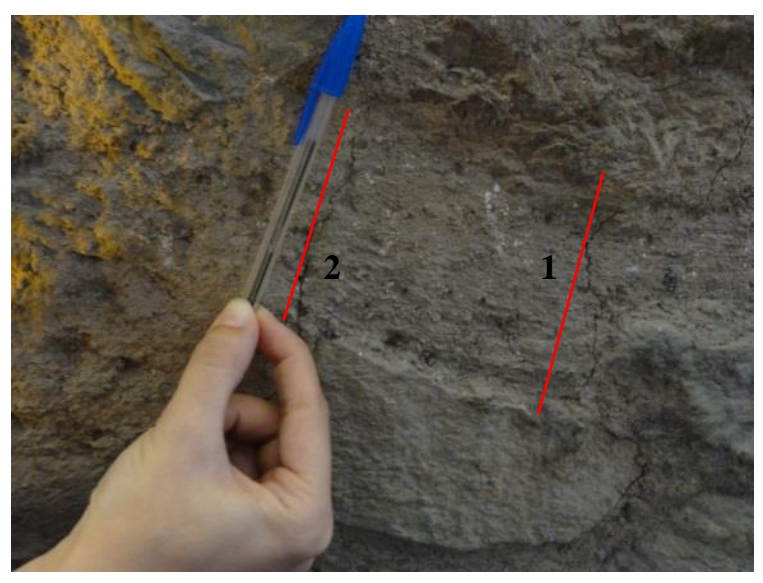

Figure 12 - The two cracks on the back surface. 


\section{Conclusions}

First of all, held out the mapping of specific surfaces on the monument by allocating the ultrasonic velocities ( $\mathrm{Vp} \mathrm{m} / \mathrm{sec}$ ), using the SURFER device detector. It is observed a wide range of values of the velocities between 500 and $6000 \mathrm{~m} / \mathrm{sec}$ depending on the case. On the other hand, the depth of the weathered zones of the tomb, were estimated by using the PUNDIT ultrasonic non-destructive digital tester. The weathering depth has a minimum value, $\mathrm{D}=35 \mathrm{~mm}$ and a maximum one, $\mathrm{D}=92,4$ $\mathrm{mm}$ with corresponding minimum velocities $800-1000 \mathrm{~m} / \mathrm{sec}$. Finally, two cracks were located and measured on the back surface of the monument, with the SURFER device and the depth of which was determined in $\mathrm{D}=88 \mathrm{~mm}$ and $\mathrm{D}=45 \mathrm{~mm}$.

\section{Acknowledgements}

The authors would like to thank the Rector of AUTH for his support to perform the present investigation, and the civil engineer Arampelos Nikolas for his valuable help for the construction of the 3D model of monument in AutoCAD.

\section{References}

Bruneau, C., Forrer, A. and Cuche, A., 1995. Une mèthode d'investigation non destructive des materieaux pierreux: les mésures à l' ultrason. Proceedings of the Congr, LCP '95, Preserv. and Restor. of Cultur. Heritage, Montreux, 187-195.

Christaras, B., 2009. P-wave velocity and quality of building materials, Proceedings of the $3 r d$ IASME / WSEAS International Conference on GEOLOGY and SEISMOLOGY (GES'09).

Marki, E., 2001. Palaiochristian and Byzantine ancient monuments in the AUTH campus area, Thessalonikewn Polis, 6. 